Article

\title{
Experimental Evaluation of Rootstock Clamping Device for Inclined Inserted Grafting of Melons
}

\author{
Kang $\mathrm{Wu}^{1}{ }^{1}$, Jianzhong Lou ${ }^{2}$, Chen $\mathrm{Li}^{1}$ and Jianping $\mathrm{Li}^{1}{ }^{1, *}$ \\ 1 College of Biosystems Engineering and Food Science, Zhejiang University, Hangzhou 310058, China; \\ kang_wu@zju.edu.cn (K.W.); lichen2020@zju.edu.cn (C.L.) \\ 2 School of Additive Manufacturing, Zhejiang Institute of Mechanical \& Electrical Engineering, \\ Hangzhou 310053, China; loujianzhong@zime.edu.cn \\ * Correspondence: jpli@zju.edu.cn
}

check for updates

Citation: Wu, K.; Lou, J.; Li, C.; Li, J. Experimental Evaluation of Rootstock Clamping Device for Inclined Inserted Grafting of Melons. Agriculture 2021, 11, 736. https:// doi.org/10.3390/agriculture11080736

Academic Editors: José Pérez-Alonso and Massimo Cecchini

Received: 25 June 2021

Accepted: 30 July 2021

Published: 2 August 2021

Publisher's Note: MDPI stays neutral with regard to jurisdictional claims in published maps and institutional affiliations.

Copyright: (c) 2021 by the authors. Licensee MDPI, Basel, Switzerland. This article is an open access article distributed under the terms and conditions of the Creative Commons Attribution (CC BY) license (https:// creativecommons.org/licenses/by/ $4.0 /)$.

\begin{abstract}
A grafting machine is a kind of machine that can quickly graft scion to rootstock instead of manual grafting. Currently, an inclined inserted grafting machine uses the mechanical clamping method, which can easily damage the rootstock seedlings due to its high stiffness, thus, reducing the success rate of grafting. This study proposed an effective, flexible clamping device for grafting. The suction hole diameter (HD), the negative pressure (NP), and the surface inclination angle (IA) of the clamping device were studied via a single factor experiment to obtain optimal parameter ranges. Optimal HD, NP, and IA were $2-3 \mathrm{~mm}, 4-8 \mathrm{kPa}$, and $10-20^{\circ}$, respectively. The orthogonal experiment results showed that the optimal parameter combination for maximum holding success rate was $H D$, $2.5 \mathrm{~mm}$; NP, $6 \mathrm{kPa}$; and IA, 10 ${ }^{\circ}$. The experimental verification was carried out using the optimal parameter combination, with a holding success rate of $98.3 \%$ and no damage. This study provides a reference for the optimal design of an inclined inserted grafting machine.
\end{abstract}

Keywords: inclined inserted grafting; mechanical damage; flexible holding; orthogonal experiment; optimal design

\section{Introduction}

Watermelon, belonging to Citrillus lanatus, is a cash crop grown worldwide, especially in China. China planted watermelon on about 1.85 million hectares (ha) in 2017, yielding 74.84 million tons, accounting for $53.3 \%$ and $67.4 \%$ of the global planting and production, respectively [1]. Watermelon contains rich nutrients, such as minerals, vitamins, and amino acids [2,3]. Because of the limited cultivated land available and the low payoffs of crop rotation, watermelons are commonly continuously grown in the same field to meet the consumer demand. However, the continuous planting leads to the establishment of Fusarium wilt, significantly affecting watermelon production $[4,5]$. Fusarium wilt can cause rapid withering of plant cotyledons and fruits [6-8]. Although Fusarium wilt is controllable by crop rotation and not using land for a period, the farmers need the income. Developing resistant varieties against Fusarium wilt could be an effective and friendly measure to control Fusarium wilt disease in watermelon [9]. However, no commercial resistant varieties have been developed currently [5]. Grafting, an innovative and friendly technology [10], can produce high yield and strong resistance to Fusarium wilt disease [11], and it is commonly used in continuous planting worldwide. Planting grafted watermelons can increase the yield and production due to the strong rooting system [12], about $30-50 \%$ higher than that of ungrafted watermelons [13].

Traditional watermelon grafting was by hand, which is labor-intensive and inefficient. The emergence of grafting robots has attracted attention of many scholars due to continuous development of science and technology [14-16]. In China, the watermelon grafting machine mainly uses two methods [17]: splice and inserted methods, as shown in Figure 1. The splice method is to cut both the rootstock and the scion into bevels, then fix the two bevels 
together with a grafting clamp. The inserted method is first removing the growth point of rootstock, then punching a hole in the rootstock using a needle. In order to insert the scion into the hole smoothly and ensure that the scion will not loosen after being inserted into the hole without a grafting clamp, the size of the needle should be as thick as the scion. Next, cut the stem at 10-15 mm below the scion cotyledon into a splice of $70^{\circ}$, and then insert the scion into the rootstock [18]. When the punching needle is extracted, the diameter of the hole in the rootstock becomes smaller due to the rebound of the tissue in the hole. After inserting the scion into the rootstock, since the diameter of the scion is close to the hole diameter, the scion fits closely with the hole in the rootstock. Therefore, compared with the splice method, the inserted method does not require a grafting clamp during grafting. The inserted method consists of the straight inserted method and the inclined inserted method. Compared with the straight inserted method, the scion is not easy to insert into the cavity (a stem structure of melons) of the rootstock using the inclined inserted method. The inclined method can prevent self-rooting and also can prevent the nutrients loss caused by the splice method. This study is based on the inclined inserted method. The design of the rootstock clamping device directly affects the success of punching a hole in the rootstock and the union of the rootstock and the scion, thus, the rootstock clamping device is a key component in the inclined inserted melon vegetables grafting machine. Lou et al. [19] designed an adaptive pressing mechanism for rootstock cotyledons using the inclined inserted method. The springs are arranged at both ends of the clamping mechanism, automatically adjusting the position during the clamping process. However, clamping parts in the middle of the clamping mechanism are rigid and can damage the rootstock stems. Yang et al. [20] proposed a kind of air suction clamp for rootstock. The mechanism uses negative pressure to hold the rootstock cotyledon for making flat; however, too many suction holes and larger negative pressure cause greater energy consumption.

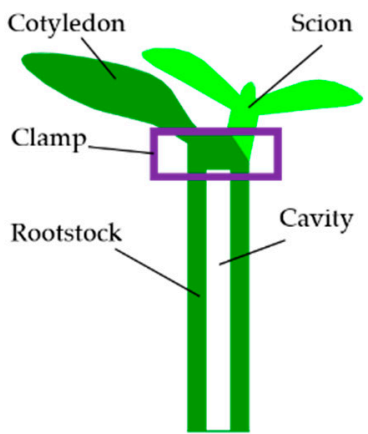

(a)

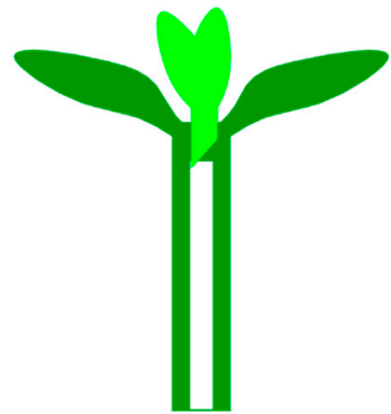

(b)

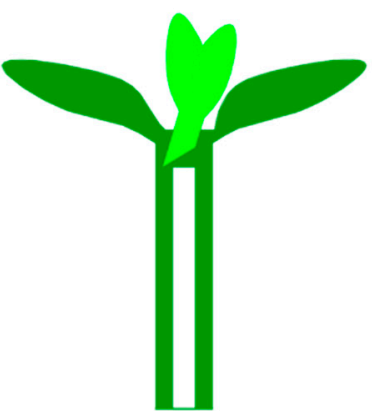

(c)

Figure 1. Grafting methods of melon vegetables: (a) Splice grafting method; (b) Straight inserted grafting method; (c) Inclined inserted grafting method.

This study proposed an effective, flexible clamping device for successful inclined inserted rootstock clamping. The device was equipped with silicone rubber to prevent the rootstock stem damage during clamping. The rootstocks were then held on the clamping block via a seedling pressing mechanism and negative pressure. The rootstock clamping device test-bed was designed, and the structural parameters and working parameters of the key components were optimized through experimental analysis. The device was experimentally verified for the optimal parameter combination. This study provides a reference for the rootstock clamping analysis in an inclined inserted grafting machine.

\section{Materials and Methods}

\subsection{Inclined Inserted Grafting Method}

The process of inclined inserted grafting method shown in Figure 2 are as follows. Firstly, the scion seedling is manually placed in the scion feeding mechanism and held by the negative pressure inside the air suction fixing device (Figure 2a). Then, the stem at $10 \mathrm{~mm}$ below the scion cotyledon is quickly cut off the splice with a cutter (Figure 2b,c). 
Meanwhile, in another position of the grafting machine, the rootstock seedling is manually placed in the clamping blocks and then held by the clamping device (Figure 2d). The clamping device mainly consists of a seedling pressing mechanism and a clamping mechanism. The growth point of rootstock is completely exposed when removing the seedling pressing mechanism (Figure 2e). The growth point removal mechanism moves according to the designed trajectory to remove the rootstock growth point (also known as apical meristem, can produce new leaves and buds.), and the root of the rootstock is cut off quickly using a cutter (Figure 2e). As new roots after root cutting grow more vigorously, the root of rootstock is generally cut off during grafting. After rotating the rootstock clamping device by $90^{\circ}$, a pneumatic cylinder drives a needle $(2.5 \mathrm{~mm}$ diameter in this study) that is as thick as the scion to punch a hole in the rootstock (Figure 2f). Next, the air suction fixing device drives the scion to the union position and inserts the scion into the rootstock diagonally downward as the needle is extracted (Figure 2g). Due to the close diameters between the scion and the hole in the rootstock, the scion fits closely in the hole in the rootstock and will not loosen after being inserted into the rootstock. Therefore, the grafted seedling does not require a grafting clamp. The grafted seedling is removed from the grafting machine and the grafting action is completed (Figure $2 \mathrm{~h}$ ).

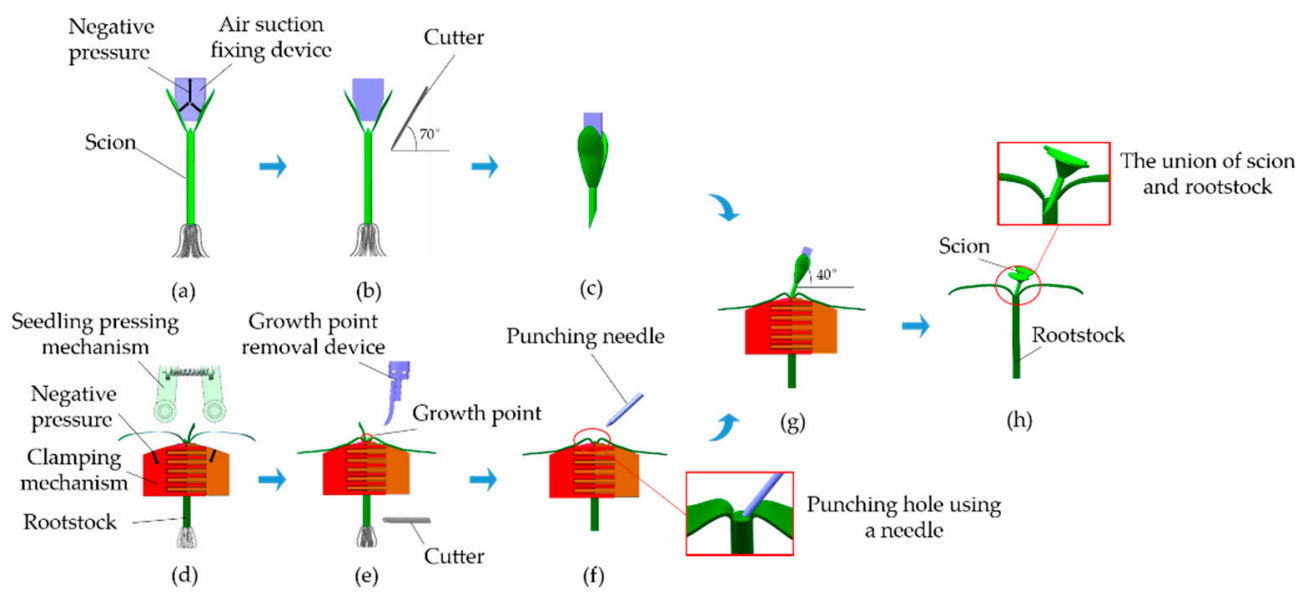

Figure 2. Grafting process of inclined inserted grafting method: (a) holding the scion; (b) cutting the stem of scion; (c) the scion after cutting; (d) holding the rootstock; (e) cutting the root and removing the growth point of rootstock; (f) punching a hole in the rootstock; (g) inserting the scion into the rootstock; (h) seedling after grafting.

The rootstock clamping device is one of the essential components of the grafting machine. Inaccurate positioning of the rootstock and the inability to fully expose the growth point during the clamping process will increase the difficulty of removing the growth point. Therefore, it is necessary to study the rootstock clamping device.

\subsection{Structure and Working Principle of Rootstock Clamping Device}

\subsubsection{Structure of Rootstock Clamping Device}

The 3D model of the rootstock clamping device is shown in Figure 3. The device consists of cylinders, seedling pressing mechanism, clamping blocks, frame, and other components. In pneumatic transmission, the external air pressure pushed the piston in the cylinder to reciprocate and then drives the actuator fixed at one end of the piston rod to move linearly or swing back and forth [21]. Pneumatic cylinder "a", fixed on the frame, can drive the pneumatic cylinder " $\mathrm{b}$ " and the seedling pressing mechanism to move directly above the clamping blocks. The function of the seedling pressing mechanism is to press the cotyledons of the rootstock seedling to the upper surface of the clamping blocks to facilitate holding the cotyledons. The rotary table cylinder is fixed on the cylinder fixing frame, and the clamping block " $\mathrm{a}$ " and the clamping block " $\mathrm{b}$ " are connected with the rotary table cylinder through the connecting frame. The rotary table cylinder can drive the clamping blocks to rotate to another direction so as to facilitate the union of scion and 
rootstock. Silicone rubber, shown in Figure 4, is fixed by glue at the middle of the clamping block, and it is food grade and belongs to low hardness silicone rubber with a hardness of $10^{\circ}$. Squeezing silicone rubber causes its deformation to cushion the clamping impact.

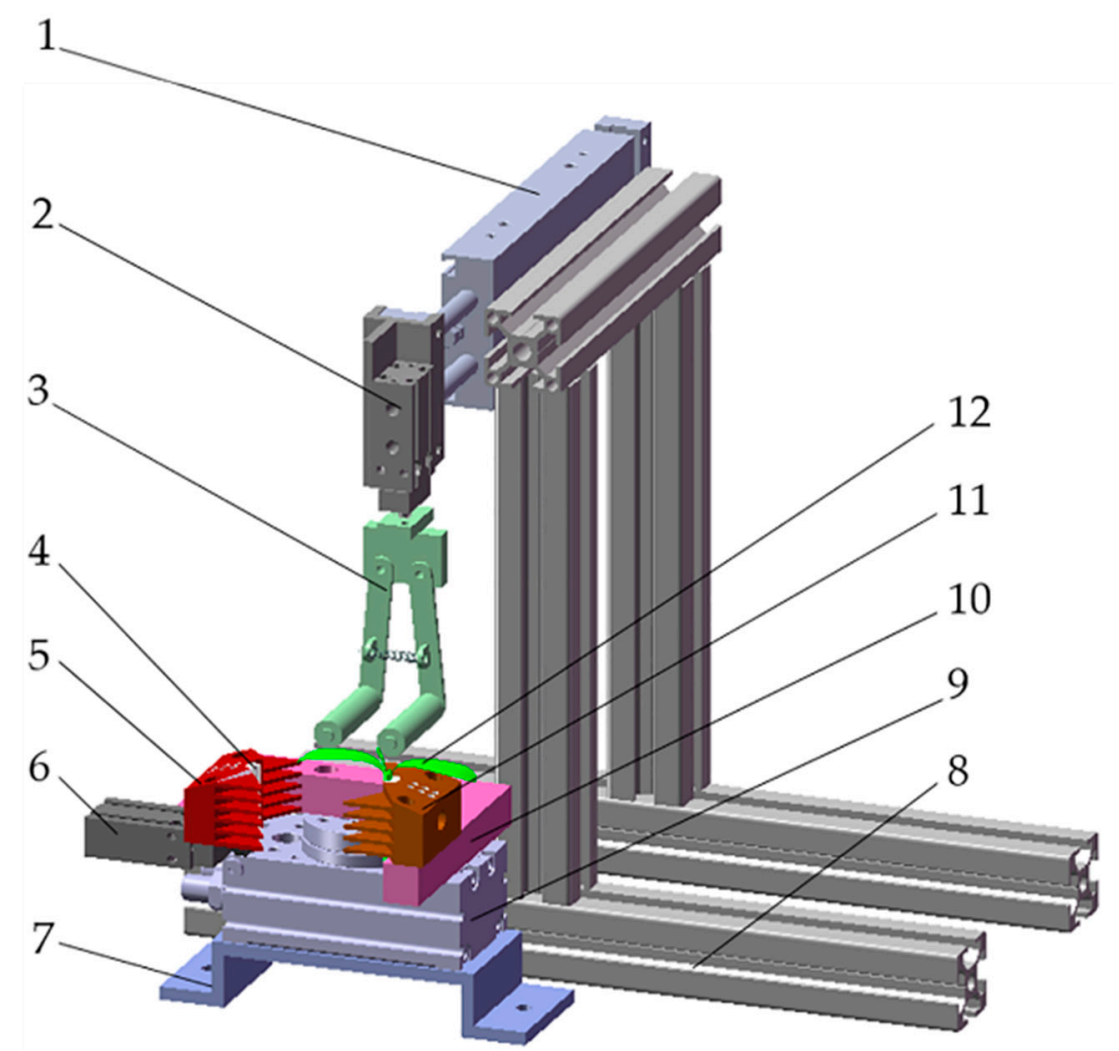

Figure 3. 3D model of rootstock clamping device. 1. Pneumatic cylinder "a". 2. Pneumatic cylinder " $\mathrm{b}$ ". 3. Seedling pressing mechanism. 4. Silicone rubber. 5. Clamping block "a". 6. Pneumatic cylinder " $c$ ", 7. Cylinder fixing frame, 8. Frame. 9. Rotary table cylinder. 10. Connecting frame. 11. Clamping block " $b$ ". 12. Rootstock seedling.

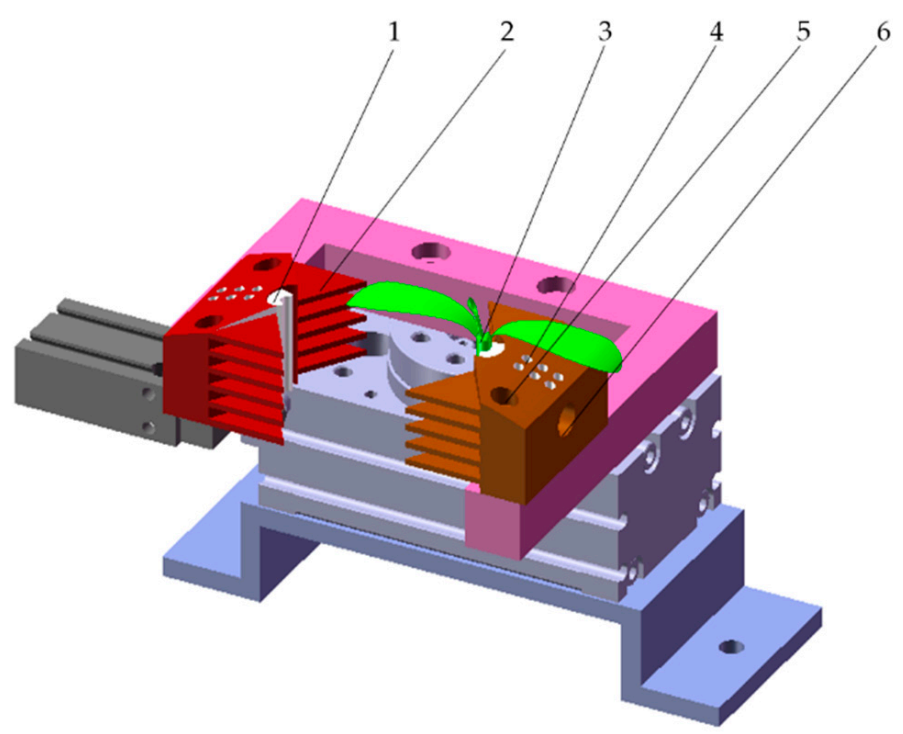

(a)

Figure 4. Cont. 


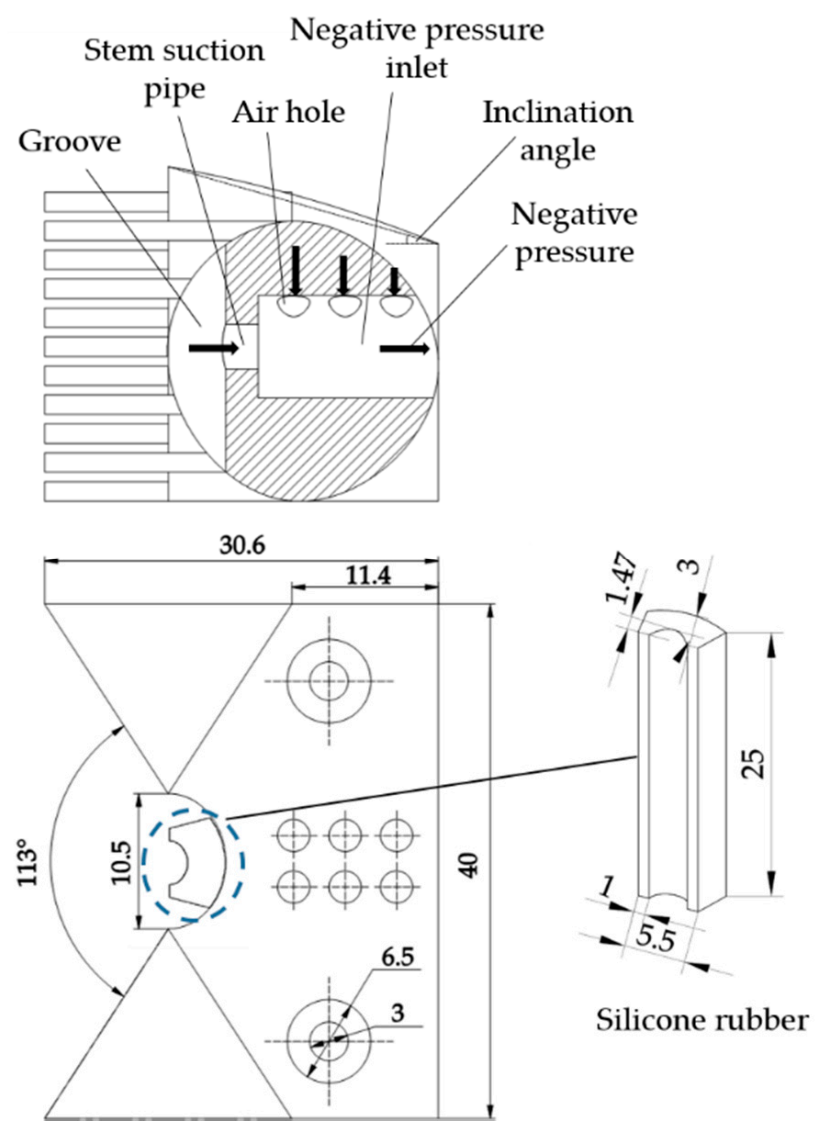

(b)

Figure 4. Clamping mechanism: (a) 3D model of Clamping mechanism; (b) engineering drawing of clamping block " $b$ " (unit: $\mathrm{mm}$ ). 1. Silicone rubber. 2. Positioning piece. 3. Seedling. 4. Air hole. 5. Connecting hole. 6. Negative pressure inlet.

\subsubsection{Working Principle}

The rootstock seedling is manually placed on the silicone rubber fixed inside the clamping block " $\mathrm{b}$ ", and then the negative pressure (in Figure $4 \mathrm{~b}$ ) generated by the vacuum pump holds the stem of the rootstock. The pneumatic cylinder " $\mathrm{c}$ " pushes the clamping block "a" towards the rootstock seedling. The v-shaped positioning pieces (in Figure 4a) on two clamping blocks can cross together and gather the stem in the middle, realizing the clamping positioning. After fixing the stem of the rootstock, the pneumatic cylinder " $a$ " pushes the pneumatic cylinder " $b$ " directly above the rootstock seedling, making the seedling pressing mechanism press down the rootstock cotyledons. The negative pressure holds the cotyledons when the cotyledons are pressed on the upper surface of the clamping blocks, and the seedling pressing mechanism completes seedling pressing and returns to its original position. The growth point is fully exposed and the clamping action completes, waiting for the follow-up growth point removal operation.

\subsubsection{Design of Clamping Mechanism}

The clamping mechanism is shown in Figure 4. The fit degree between the cotyledon and the upper surface of the clamping block is one of the key factors for the holding success. The upper surface of the clamping block is curved at an inclination angle of 5-25. The two rows of air holes (diameter, 1.5-3.5 mm) are arranged on the upper surface. The distances between the two rows of air holes are larger than the leaf vein width in the middle of the cotyledons to ensure that the cotyledons are effectively held. At the same time, to avoid the waste of negative pressure, the total width of two rows of air holes is less than the cotyledon width. The negative pressure inlet (diameter, $8 \mathrm{~mm}$ ) at one end is connected 
with the negative pressure pipe. Compared to clamping block "a", a stem suction pipe is set in the clamping block " $\mathrm{b}$ ", and other structural parameters of clamping block " $\mathrm{b}$ " are the same as those in clamping block "a". Silicone rubber is then put in the middle groove of the clamping block. A hole connected with the stem suction pipe of the clamping block " $b$ " is designed inside the silicone rubber. The silicone rubber is smaller than the groove size to achieve silicone rubber deformation space after squeezing.

The straight stems can be fixed at the middle of the clamping block only by suction. It is necessary to locate the curved stems using other methods since negative pressure can not completely hold and fix the stems in the middle position [22]. In this study, the multi-layer positioning pieces are arranged on the clamping block to realize the curved stems positioning.

The force of the rootstock stem in the clamping process is shown in Figure 5.

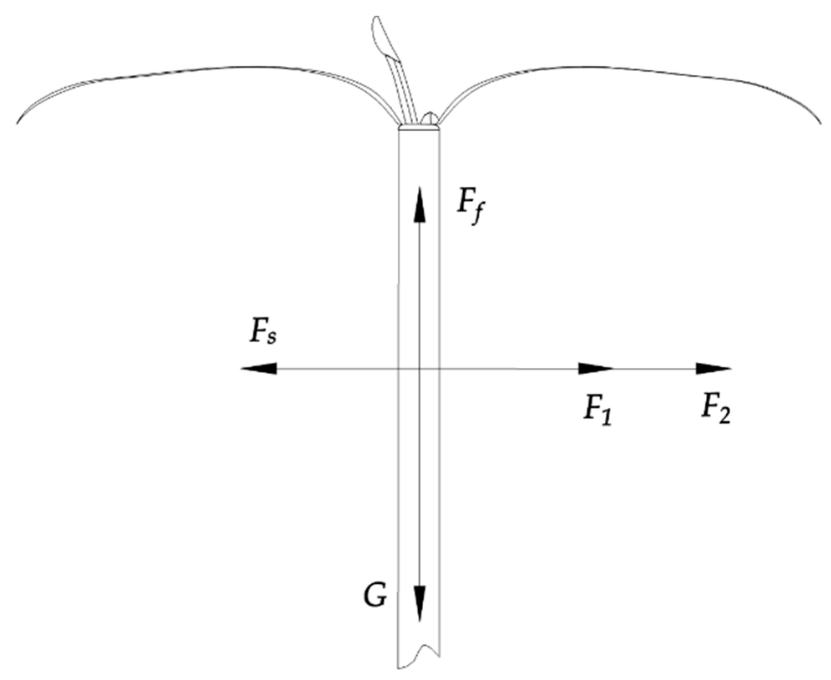

Figure 5. The force diagram of the rootstock stem.

Assuming that the force of the stem reaches an instant balance, the force equation can be expressed as:

$$
\begin{gathered}
\left\{\begin{array}{l}
F_{s}=F_{1}+F_{2} \\
G=F_{f}
\end{array}\right. \\
\left\{\begin{array}{l}
F_{f}=\mu F_{s} \\
F_{1}=P S=\pi P r^{2}
\end{array}\right.
\end{gathered}
$$

Formulas (1) and (2) can be obtained using the following formula:

$$
\frac{F_{1}}{S}+\frac{F_{2}}{S_{0}}=P+\frac{G-\pi \mu P r^{2}}{\mu S_{0}}
$$

$F_{S}$-The supporting force of silicone rubber to the stem, $\mathrm{N}$;

$F_{1}$ - The air suction pressure, $\mathrm{N}$;

$F_{2}$ - The impact force of clamping block "a" to the stem, N;

$G$-The rootstock seedlings gravity, N;

$F_{f}$-The friction force between silicone rubber and the stem, N;

$\mu$-The friction coefficient between silicone rubber and the stem;

$P$-Negative pressure, $\mathrm{Pa}$;

$S$ - The contact area between the suction hole and the stem, $\mathrm{m}^{2}$;

$r$-The radius of suction hole, $r=1.75 \mathrm{~mm}$;

$S_{0}$-Pressure area of the stem, $\mathrm{m}^{2}$;

$\pi-\mathrm{Pi}, \pi=3.14$.

Stress generated by $F_{1}$ and $F_{2}$ should not be greater than yield stress of the stem to ensure that the rootstock stem is not pinched during the clamping process. Therefore, at 
constant $\mu, G$, and $r$, it is necessary to study the air suction negative pressure change in the Equation (3).

\subsubsection{Design of Seedling Pressing Mechanism}

The structure of the rootstock seedling pressing mechanism is shown in Figure 6. The seedling pressing mechanism contains connecting block, connecting rod, spring, bearing, shaft, bearing retaining ring, and seedling pressing rod. Pneumatic cylinder " $\mathrm{b}$ " is fixed on one end of the rootstock seedling pressing mechanism through the connecting block, controlling the up and down movement of the seedling pressing rod. The seedling pressing rod is installed on the shaft through the bearing, and the outer end of the bearing is equipped with a bearing retaining ring. Pneumatic cylinder " $b$ " drives the seedling pressing mechanism downwards during operation, pushing the seedling pressing rod down after touching the cotyledons of the rootstock. The friction between the seedling pressing rod and the cotyledons rotates the seedling pressing rod, moving along the extension direction of the cotyledons. The spring in the middle of the two connecting rods adjusts the horizontal movement distance of the seedling pressing rod. It quickly restores the seedling pressing rod to its original position after seedling pressing.

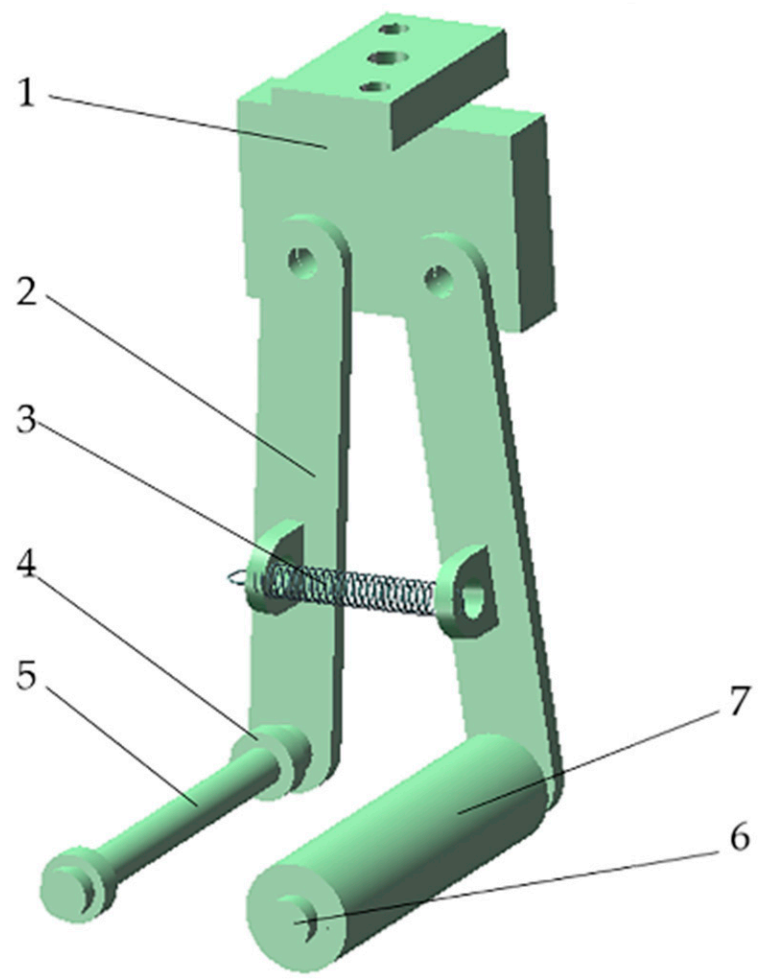

Figure 6. 3D model of seedling pressing mechanism. 1. Connecting block. 2. Connecting rod. 3. Spring. 4. Bearing. 5. Shaft. 6. Bearing retaining ring. 7. Seedling pressing rod.

The force on a single cotyledon during seedling pressing is shown in Figure 7. The cotyledon force equation at equilibrium moment can be expressed as:

$$
\begin{gathered}
\left\{\begin{array}{c}
G \cos \alpha+F_{p}+F_{a}=F_{n} \\
G \sin \alpha+F_{f 2}=F_{f 1}
\end{array}\right. \\
\left\{\begin{array}{c}
F_{f 1}=\mu_{1} F_{p} \\
F_{f 2}=\mu_{2} F_{n} \\
F_{a}=P_{0} S_{1}=n P_{0} \pi r_{0}{ }^{2}
\end{array}\right.
\end{gathered}
$$




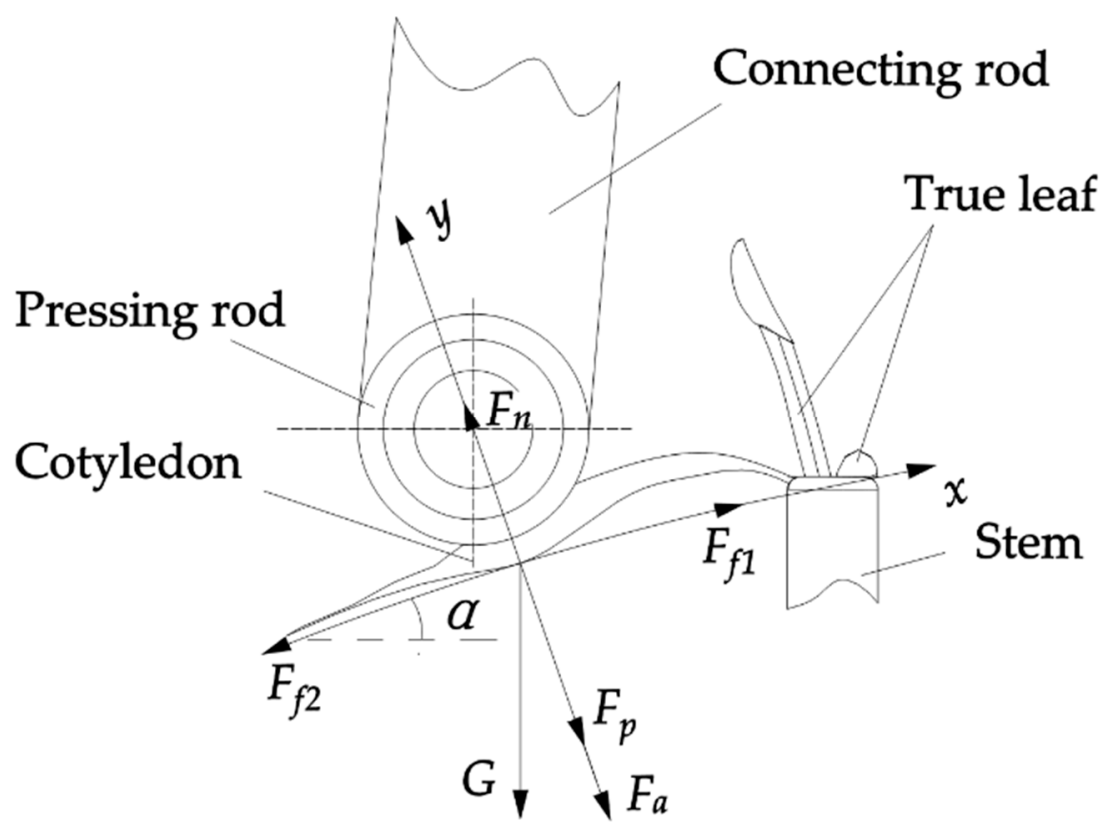

Figure 7. Stress analysis of a single cotyledon.

Then,

$$
\frac{F_{a}}{S_{1}}+\frac{G \cos \alpha+F_{p}}{S_{2}}=P_{0}+\frac{G \sin \alpha+\mu_{1} G \cos \alpha+n \mu_{2} P_{0} \pi r_{0}^{2}}{S_{2}\left(\mu_{1}-\mu_{2}\right)}
$$

G-The cotyledon gravity, N;

$\alpha$-The surface inclination angle of the clamping block, ${ }^{\circ}$;

$F_{p}$-The force of the pressing rod on the cotyledon, N;

$F_{a}$-The air suction pressure, $\mathrm{N}$;

$F_{n}$-The supporting force of the clamping block to the cotyledon, N;

$F_{f 1}$-The friction force between the pressing rod and cotyledon, $\mathrm{N}$;

$F_{f 2}$-The friction force between the clamping block surface and the cotyledon, N;

$\mu_{1}$-The friction coefficient between cotyledon and pressing rod;

$\mu_{2}$-The friction coefficients between cotyledon and clamping block surface;

$P_{0}-$ Negative pressure, $\mathrm{Pa}$;

$S_{1}$ - The contact area between suction hole and cotyledon, $\mathrm{m}^{2}$;

$r_{0}$-The radius of suction holes on the surface of the clamping block, $\mathrm{m}$;

$n$-The number of suction holes, $n=6$;

$S_{2}$-Pressure area of the cotyledon, $\mathrm{m}^{2}$;

Stress of cotyledon should not be greater than the yield stress of cotyledon to ensure that cotyledons are not crushed. Equation (6) indicates that the pressure of the pressing rod on the cotyledon is related to the surface inclination angle of the clamping block, the negative pressure, and the suction hole diameter. Therefore, it is necessary to investigate the above parameters to reduce the seedling damage and further optimize the design of the clamping device.

\subsection{Experiment Materials}

Yongzhen No. 5 cucurbit, a special rootstock for watermelon (Top-Yield Seed Technology Co., Ltd., Ningbo, China), was selected as the experimental material. The rootstock seedling shown in Figure 8 was planted in a greenhouse at $22-26^{\circ} \mathrm{C}$ for $9-12$ days, and the characteristic parameters of rootstock seedlings are shown in Table 1 . The watermelon variety "Zaojia 8424" was used as the scion. The experiment was conducted when the cucurbit seedlings had two leaves (one true leaf unfolded and the second true leaf exposed). 


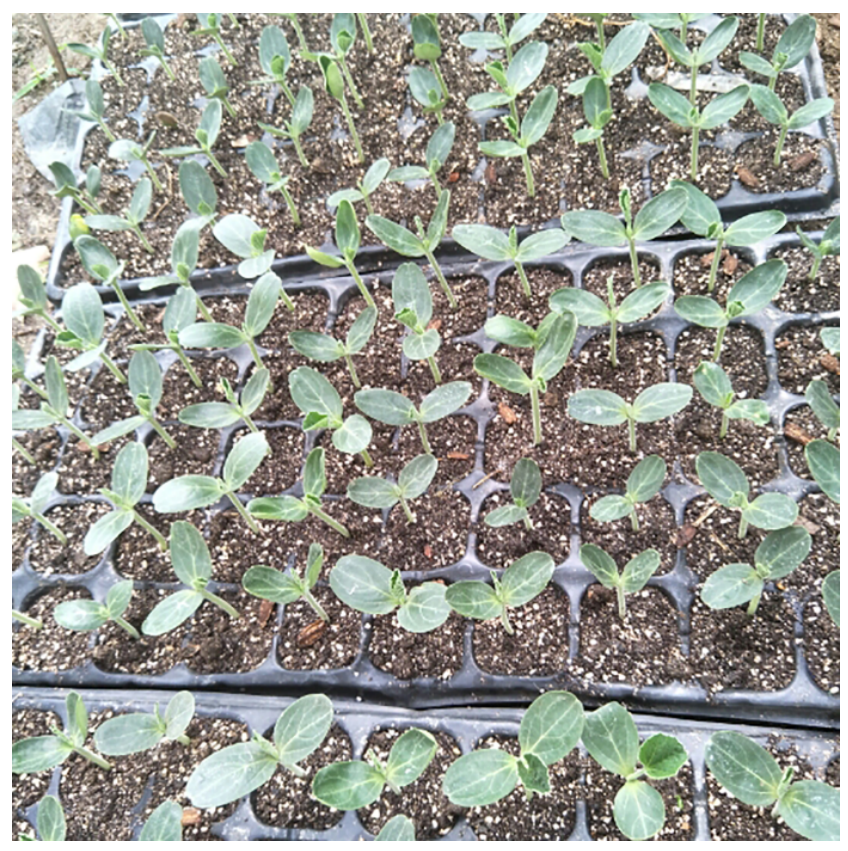

(a)

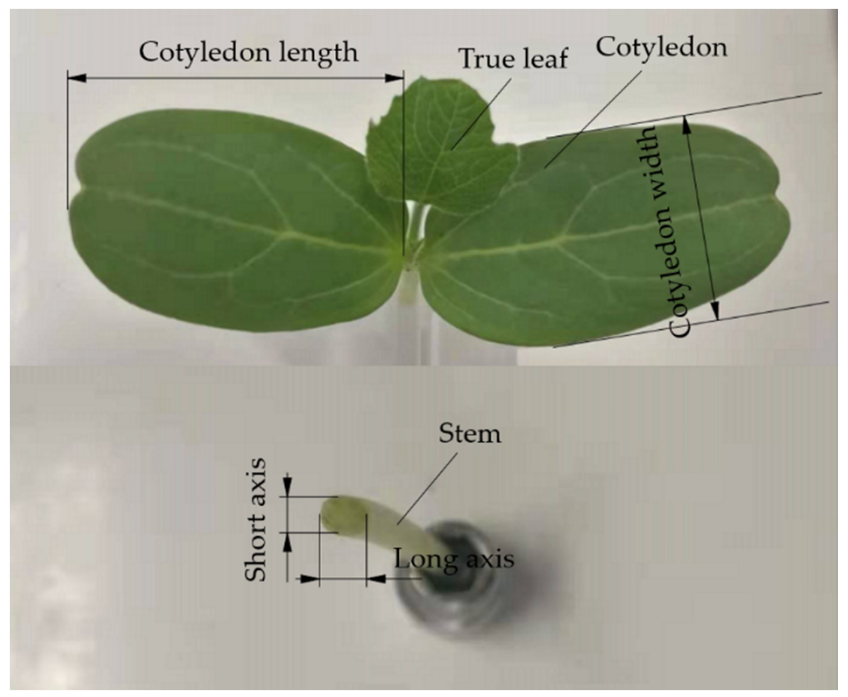

(b)

Figure 8. Rootstock seedlings: (a) rootstock seedlings in a greenhouse; (b) structure of single rootstock seedling.

Table 1. Characteristic parameters of rootstock.

\begin{tabular}{cccc}
\hline Long Axis of Stem $(\mathbf{m m})$ & Short Axis of Stem $(\mathbf{m m})$ & Cotyledon Width $(\mathbf{m m})$ & Single Cotyledon Length $(\mathrm{mm})$ \\
\hline $3.52 \pm 0.29$ & $2.94 \pm 0.29$ & $20.23 \pm 1.84$ & $32.37 \pm 3.29$ \\
\hline
\end{tabular}

The 3D model of clamping blocks were designed in SolidWorks (Dassault Systemes, Concord, MA, USA) and then imported into a 3D printer (CR5080, Creality 3D Technology Co., Ltd., Shenzhen, China). The clamping blocks were made using 3D printing with polylactic acid (PLA). The fabrication process of silicone rubber was that the liquid silicone rubber was poured in a mold and cured at a room temperature of $28{ }^{\circ} \mathrm{C}$ for $4-5 \mathrm{~h}$. The experiment gas sources included a Boge air compressor (pressure range 0-10 bar) and vacuum pump (pressure range $-8-0$ bar). 


\subsection{Experiment Conditions and Methods}

The experiment was conducted on the self-made rootstock clamping test-bed to analyze the influence of the actual working environment and optimize the operating parameters. The vacuum pump produced negative pressure to hold the stem of rootstock on the clamping block. Another clamping block was pushed by the pneumatic cylinder to clamp the rootstock. The seedling pressing mechanism pressed down the cotyledons of rootstock, and then the cotyledons were held by the negative pressure of air holes. The rootstock holding process is shown in Figure 9. The negative pressure pipe was connected with a digital display meter to display the negative pressure value. The positive air pressure produced by the air compressor moved the pneumatic cylinder to control the clamping block and the seedling pressing mechanism. The air pressure pipe had a pressure regulating valve, which controlled the pressure.

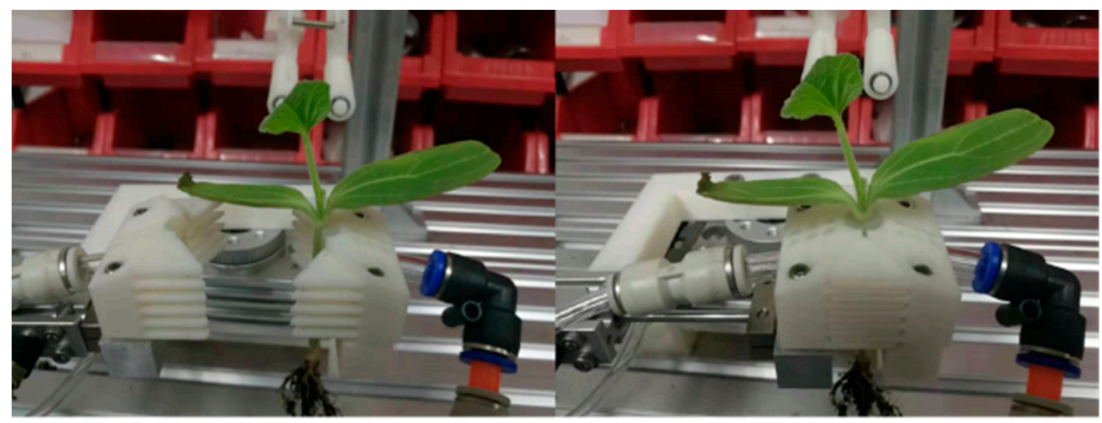

(a) Holding rootstock

(b) Clamping rootstock

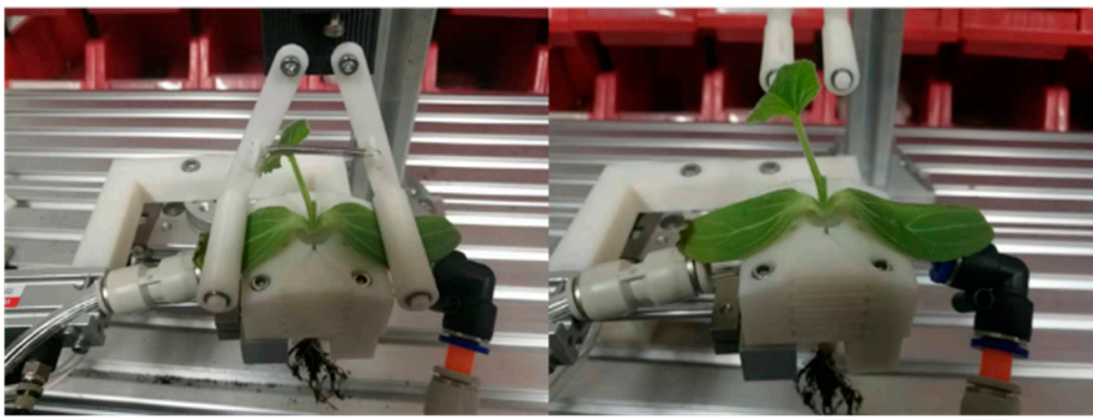

(c) Pressing cotyledon

(d) Experiment completed

Figure 9. Diagram of rootstock holding process.

\subsection{Experimental Factors and Indicators}

The clamping test-bed was used to investigate the adsorption effect of the rootstock clamping device. Previous experiments and studies [23] have shown that air suction hole diameter (HD), negative pressure value (NP), and surface inclination angle (IA) are the main experimental factors. The holding success rate and the damage rate of rootstock were used as the experimental indicators. Rootstock seedlings held on the clamping blocks with no damage were treated as successful experiments; otherwise, they were recorded as failed. Obvious extrusion marks or breakage on the stems or cotyledons of rootstock seedlings were regarded as experimental damage. The damage rate included the damage to the stems and cotyledons of rootstocks. The indicators were calculated as follows.

$$
\left\{\begin{array}{l}
P=\frac{n_{0}}{N} \\
Q=\frac{n_{1}}{N}
\end{array}\right.
$$

$P$-The holding success rate, \%;

$n_{0}$-The number of failed cotyledons of rootstocks;

$\mathrm{N}$-The number of rootstocks; 
$Q$ - The damage rate of rootstocks, $\%$;

$n_{1}$-The number of damaged rootstocks.

\subsection{Experimental Design}

This experiment selected HD, NP, and IA as influencing factors and the success rate and the damage rate as experimental indicators. Each factor had five levels: HD from 1.5 to $3.5 \mathrm{~mm}$ in increments of $0.5 \mathrm{~mm}$, NP from 2 to $10 \mathrm{kPa}$ in increments of $2 \mathrm{kPa}$, and IA from 5 to $25^{\circ}$ in increments of $5^{\circ}$. The influence of the experimental factors on clamping was studied via a single factor experiment and orthogonal experiment. The orthogonal experiment could analyze the significant influence of each experiment factor on the experiment indicators through a small number of representative experiments and found out the optimal combination of factor levels [24], which has been applied in many fields $[25,26]$. The factor level table of the orthogonal experiment is shown in Table 2. A total of 15 groups of single factor experiments and nine groups of orthogonal experiments were carried out ( 60 rootstock seedlings in each group).

Table 2. Factors level.

\begin{tabular}{cccc}
\hline Level & HD $(\mathbf{m m})$ & NP $\mathbf{( k P a )}$ & IA $\left.\mathbf{(}^{\circ}\right)$ \\
\hline 1 & 2 & 4 & 10 \\
2 & 2.5 & 6 & 15 \\
3 & 3 & 8 & 20 \\
\hline
\end{tabular}

\subsection{Data Analysis}

The orthogonal experiment results were processed and analyzed using the software SPSS 19.0 (IBM, Armonk, NY, USA). The analysis of variance (ANOVA) was conducted to assess the significance $(p<0.05)$ of experimental factors. The software Origin 8.5 (OriginLab, Northampton, MA, USA) was used for graphing and data analysis.

\section{Results and Discussion}

All the experiments were conducted in the laboratory of the College of Biosystems Engineering and Food Science, Zhejiang University, China. However, there were potential limitations in this study. First, compared with the actual facility agriculture grafted operation, the sample of this study is relatively small. Second, this study just investigates the rootstock clamping device, and no attempt has been made to study the device in the grafting machine; therefore, there could be other factors that affect the desired properties of the rootstock clamping device. Thus, a profound study is warranted in the future. Nonetheless, since fewer studies are available on the rootstock clamping device currently, these results could be helpful for the research of flexible clamping devices.

\subsection{Single-Factor Experiment Analysis and Discussion}

The single-factor experimental results of HD are shown in Figure 10. The results showed that with the increase of HD, the holding success significantly increased at first, then slowed down, finally turning into a downward trend. Decreased HD increased the velocity in the air hole, reducing the adsorption effect on rootstock cotyledons due to the small suction force between the air hole and cotyledon. Similarly, increased HD increased the suction force between the air hole and cotyledons. This improved the holding success rate while gradually decreasing the flow velocity and negative pressure. The negative pressure and flow rate rapidly decreased at certain HD increments, decreasing the adsorption success rate. Similar conclusions were reported by other researchers, who found that the airflow velocity and pressure gradually decreased with increasing outlet diameter of the suction chamber $[20,27,28]$. The clamping device had a better holding effect at an HD range of $2-3 \mathrm{~mm}$. 


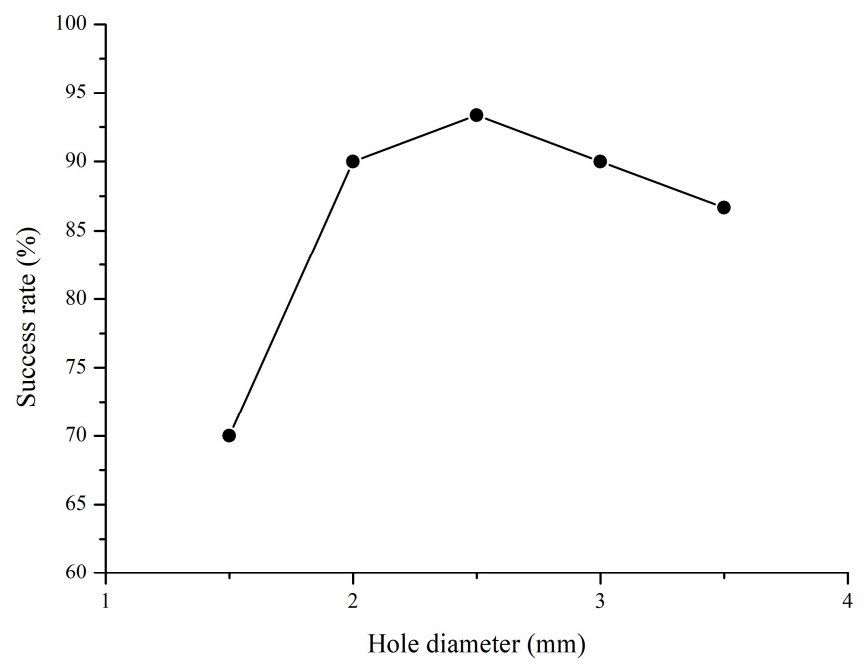

Figure 10. Relationship between hole diameter (HD) and success rate. Note: negative pressure (NP) was $4 \mathrm{kPa}$ and inclination angle (IA) was $20^{\circ}$.

The single factor experimental results of NP are shown in Figure 11. Negative pressure flowed into the stem suction pipe and air hole from the negative pressure inlet, and the seedling pressing mechanism assisted in holding the rootstock on the clamping block. It can be seen in Figure 11 that the holding success rate of rootstock gradually increased with increasing NP. The cotyledons cannot be held on the clamping block at an NP of $2 \mathrm{kPa}$ because low pressure leads to a small suction force. However, with the gradual increase of NP, this situation changed significantly. NP was caused by the pressure difference between the inside and outside of air hole. Increased NP led to increased pressure difference and decreased pressure inside the air hole. According to Bernoulli's principle, the flow velocity increased when the pressure decreased, so the flow velocity inside the air hole increased. At constant HD, increasing NP promoted the flow rate and suction force of the air hole, thus, improving the holding success rate. Jiang et al. $(2019,2020)$ obtained a similar conclusion that the increase of negative pressure increased the vacuum in the gas chamber, thus, increasing the flow rate and improving the adsorption capacity [29,30]. In this experiment, the injury of rootstock seedlings occurred mainly at the junction between cotyledons and stems when NP was $10 \mathrm{kPa}$, possibly due to the high NP increasing suction force. When $\mathrm{HP}$ ranged $4-8 \mathrm{kPa}$, the holding effect had satisfying values.

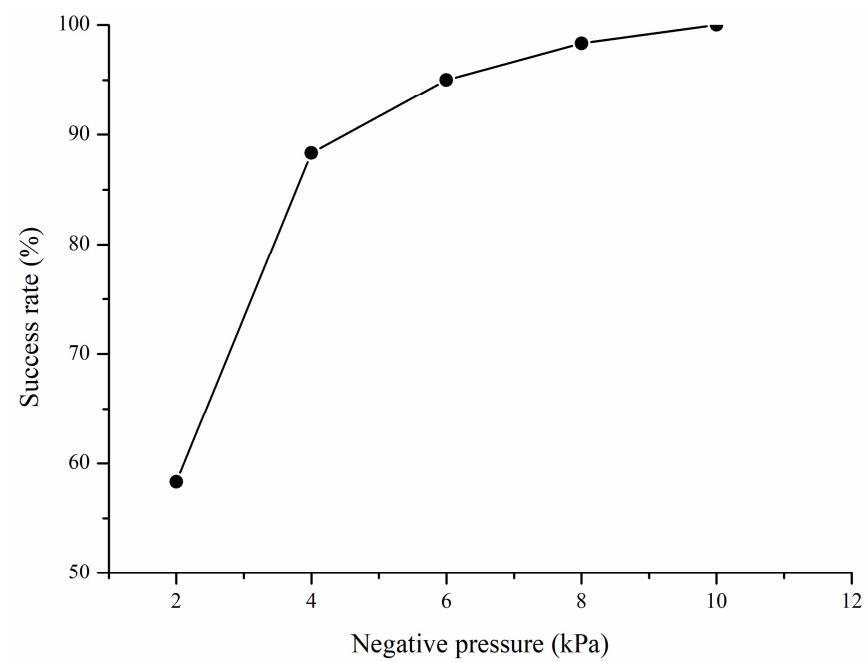

Figure 11. Relationship between negative pressure (NP) and success rate. Note: hole diameter (HD) was $2.5 \mathrm{~mm}$ and inclination angle (IA) was $20^{\circ}$. 
At a constant of NP and HD, inclination angle (IA) reflected the fit of cotyledon and the upper surface of clamping block. Excessive IA led to damage in the junction between the cotyledon and the stem during the pressing cotyledons process; additionally, the negative pressure of air holes close to the stem could not effectively hold the cotyledon. The single factor experimental results of IA are shown in Figure 12. As can be seen from Figure 12, the holding success rate showed a downward trend with increasing IA. Increased IA increased the distance of the cotyledons pressed to the surface of the clamping block, promoting the resistance of the cotyledons to the clamping block. Furthermore, increased IA reduced the fit degree between the cotyledons and the clamping block surface, resulting in some negative pressure loss, thus, reducing the adsorption effect. The holding success rate was higher when the IA was $5^{\circ}$. However, the growth point of the rootstock could not be fully exposed at $5^{\circ}$, thus, it was not conducive for the subsequent growth point removal operation. Therefore, the holding effect can be improved to an acceptable level at an IA range of $10-20^{\circ}$.

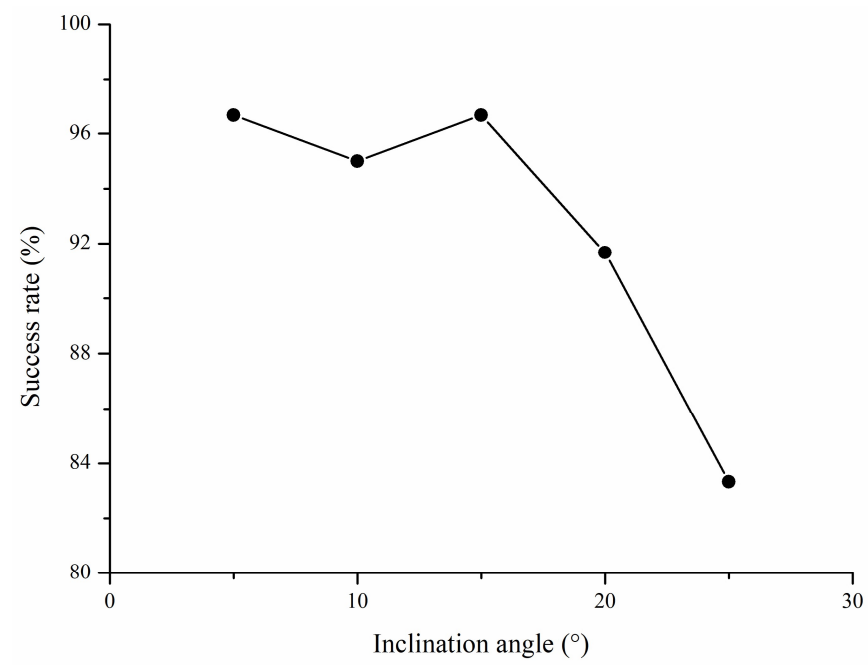

Figure 12. Relationship between inclination angle (IA) and success rate. Note: hole diameter (HD) was $2.5 \mathrm{~mm}$ and negative pressure (NP) was $4 \mathrm{kPa}$.

\subsection{Orthogonal Experiment Results and Discussion}

The significance and influence of HD, NP, and IA on holding were investigated via a three-factor, three-level orthogonal experiment using the clamping device. The experimental results are shown in Table 3.

Table 3. Results of orthogonal experiment.

\begin{tabular}{cccccc}
\hline No. & HD $(\mathbf{m m})$ & $\mathbf{N P}(\mathbf{k P a})$ & $\mathbf{I A}\left(^{\circ}\right)$ & Success Rate $(\mathbf{\%})$ & Damage Rate $(\%)$ \\
\hline 1 & 1 & 1 & 1 & 93.33 & 0 \\
2 & 1 & 2 & 2 & 95 & 0 \\
3 & 1 & 3 & 3 & 91.67 & 0 \\
4 & 2 & 1 & 2 & 96.67 & 0 \\
5 & 2 & 2 & 3 & 95 & 0 \\
6 & 2 & 3 & 1 & 98.33 & 0 \\
7 & 3 & 1 & 3 & 90 & 0 \\
8 & 3 & 2 & 1 & 96.67 & 5 \\
9 & 3 & 3 & 2 & 95 & 0 \\
\hline
\end{tabular}

The success rate of the clamping device was not less than $90 \%$ with a low damage rate, indicating an effective clamping device (Table 3). Through the experiment, it was found that the rootstock stem was deflected during clamping, inhibiting cotyledon absorption, losing some negative pressure, which led to the adsorption failure. This observation was in agreement with the results obtained by others [31]. The holding damage was due to the 
uneven cotyledons of the rootstock, and the distal end of some cotyledons were lower than the position of clamping blocks.

This study mainly focused on the holding success rate analysis since the damage rate was low. The analysis results are shown in Table 4 . Table 4 showed that the $p$-values for $\mathrm{HD}, \mathrm{NP}$, and IA were $0.032,0.072$, and 0.023 , respectively, indicating that HD and IA had a significant effect on the success rate $(p<0.05)$. By contrast, NP had no significant influence on the success rate since its $p$-value for NP was greater than 0.05 .

Table 4. ANOVA results for adsorption effect.

\begin{tabular}{cccccc}
\hline Source & Sum of Squares & df & Mean Square & F-Value & $p$-Value \\
\hline HD & 19.131 & 2 & 9.565 & 30.502 & $0.032{ }^{*}$ \\
NP & 8.031 & 2 & 4.015 & 12.804 & 0.072 \\
IA & 26.523 & 2 & 13.262 & 42.289 & $0.023^{*}$ \\
\hline Error & 0.627 & 2 & 0.314 & & \\
Total & $80,647.845$ & 9 & & & \\
${ }^{*}$ means this term is significant $(p<0.05)$. &
\end{tabular}

The F-values were compared to determine the influence order of the three factors on the experiment results. Higher F-values indicated a greater influence of the corresponding factor on the experiment results [32]. The order of influence of the three factors in this study was IA $>$ HD $>$ NP. Therefore, more attention should be on adjusting IA and HD than NP during the experiment since the influence order of NP was the last and had no significant effect on the experimental results.

As can be seen from Figure 13, the optimal combination based on achieving the maximum holding success rate was HD2, NP2, and IA1. The experimental verification was conducted using the parameter combination with 60 rootstock seedlings. The optimal parameter combination achieved a holding success rate of $98.3 \%$ with no damage, indicating an effective clamping device designed in this study, achieving grafting requirements.

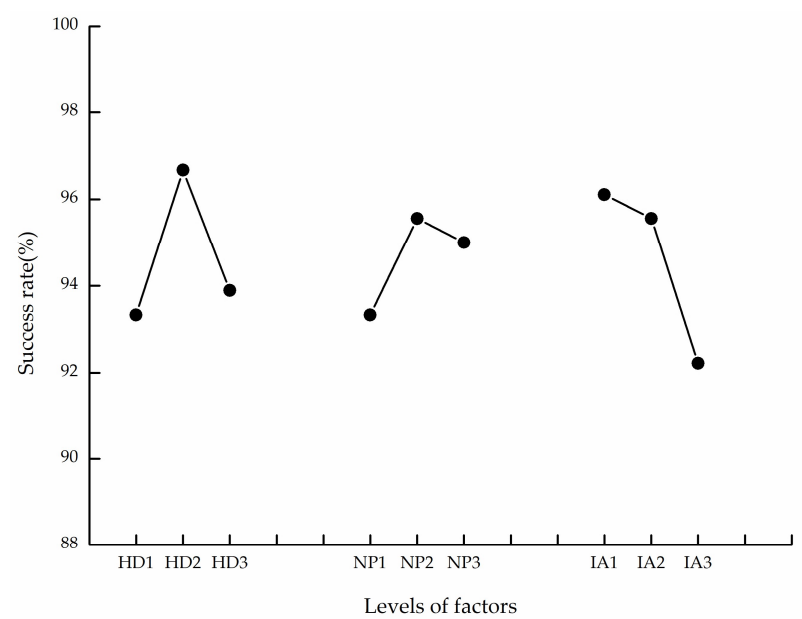

Figure 13. Comparison of effects of influencing factors on holding success rate.

\section{Conclusions}

This study proposed a flexible clamping device to reduce the holding damage of rootstock seedlings during grafting. The clamping device was evaluated to determine its performance. The following conclusions were made:

(1) The single factor experiment was used to determine the optimal factor ranges of the clamping device: $\mathrm{HD}, 2-3 \mathrm{~mm}$; $\mathrm{NP}, 4-8 \mathrm{kPa}$; and IA, $10-20^{\circ}$.

(2) The orthogonal experiment was used to assess the influence of structural parameters and working parameters on holding. The ANOVA analysis indicated the influence order as follows: IA $>\mathrm{HD}>\mathrm{NP}$. 
(3) The optimal parameter combination was determined by orthogonal experiment: $\mathrm{HD}, 2.5 \mathrm{~mm}$; NP, $6 \mathrm{kPa}$; and IA, $10^{\circ}$. The verification experiment was conducted using the parameter combination. A holding success rate of $98.3 \%$ with no damage was obtained. This study can provide a reference for the development of an inclined inserted grafting machine.

Author Contributions: Methodology, K.W. and J.L. (Jianping Li); software, K.W. and C.L.; validation, K.W.; formal analysis, K.W. and C.L.; investigation, K.W.; data curation, K.W.; writing-original draft preparation, K.W.; writing—review and editing, J.L. (Jianzhong Lou) and J.L. (Jianping Li); visualization, K.W. and C.L.; supervision, J.L. (Jianping Li); project administration, J.L. (Jianping Li); funding acquisition, J.L. (Jianping Li). All authors have read and agreed to the published version of the manuscript.

Funding: This research was funded by National Natural Science Foundation of China (Grant No. 51775490).

Institutional Review Board Statement: Not applicable.

Informed Consent Statement: Not applicable.

Data Availability Statement: The data presented in this study are available on demand from the first author at (kang_wu@zju.edu.cn).

Acknowledgments: The authors are very grateful to the members of the research group for their help in the experiment. We also appreciate the work of the editors and the reviewers of the paper.

Conflicts of Interest: The authors declare no conflict of interest.

\section{References}

1. Yang, X.; Yang, F.; Liu, Y.; Li, J.; Song, H.L. Identification of key off-flavor compounds in thermally treated watermelon juice via gas chromatography-olfactometry-mass spectrometry, aroma recombination, and omission experiments. Foods 2020, 9, 227. [CrossRef]

2. Collins, J.K.; Wu, G.; Perkins, V.P.; Spears, K.; Claypool, P.L.; Baker, R.A.; Clevidence, B.A. Watermelon consumption increases plasma arginine concentrations in adults. Nutrition 2007, 23, 261-266. [CrossRef] [PubMed]

3. Tarazona-díaz, M.; Viegas, J.; Moldao-martins, M.; Aguayo, E. Bioactive compounds from flesh and by-product of fresh-cut watermelon varieties. J. Sci. Food Agric. 2011, 91, 805-812. [CrossRef]

4. Martyn, R.D. Fusarium wilt of watermelon: 120 years of research. Hortic. Rev. 2014, 42, 349-442. [CrossRef]

5. Wu, Y.C.; Zhou, J.Y.; Li, C.G.; Ma, Y. Antifungal and plant growth promotion activity of volatile organic compounds produced by Bacillus amyloliquefaciens. MicrobiologyOpen 2019, 8, e813. [CrossRef]

6. Cohen, R.; Pivonia, S.; Burger, Y.; Edelstein, M.; Gamliel, A.; Katan, J. Toward integrated management of monosporascus wilt of melons in Israel. Plant Dis. 2000, 84, 496-505. [CrossRef] [PubMed]

7. Castro, G.; Perpiñá, G.; Esteras, C.; Armengol, J.; Picó, B.; Pérez-de-Castro, A. Resistance in melon to Monosporascus cannonballus and M. eutypoides: Fungal pathogens associated with Monosporascus root rot and vine decline. Ann. Appl. Biol. 2020, 177, 101-111. [CrossRef]

8. Xu, L.H.; Nicolaisen, M.; Larsen, J.; Zeng, R.; Gao, S.G.; Dai, F.M. Pathogen infection and host-resistance interactively affect root-associated fungal communities in watermelon. Front. Microbiol. 2020, 11, 3256. [CrossRef]

9. Keinath, A.P.; Coolong, T.W.; Lanier, J.D.; Ji, P.S. Managing Fusarium wilt of watermelon with delayed transplanting and cultivar resistance. Plant Dis. 2019, 103, 44-50. [CrossRef]

10. Aslam, A.; Zhao, S.; Azam, M.; Lu, X.; He, N.; Li, B.; Dou, J.; Zhu, H.; Liu, W. Comparative analysis of primary metabolites and transcriptome changes between ungrafted and pumpkin-grafted watermelon during fruit development. Peer J. 2020, 8, e8259. [CrossRef]

11. Rouphael, Y.; Venema, J.; Edelstein, M.; Savvas, D.; Colla, G.; Ntatsi, G.; Ben-Hur, M.; Kumar, P.; Schwarz, D. Grafting as a tool for tolerance of abiotic stress. In Proceedings of the Vegetable Grafting Principles and Practices, CAB International, Wallingford, UK, 5 June 2017; pp. 171-215. [CrossRef]

12. Aloni, B.; Cohen, R.; Karni, L.; Aktas, H.; Edelstein, M. Hormonal signaling in rootstock-scion interactions. Sci. Hortic. 2010, 127, 119-126. [CrossRef]

13. Johnson, G. Grafted Watermelons Revisited. Weekly Crop Update. University of Delaware Cooperative Extension. 2017. Available online: https: / / sites.udel.edu/weeklycropupdate/?p=10563 (accessed on 6 May 2021).

14. Chiu, Y.C.; Chen, S.; Chang, Y.C. Development of a circular grafting robotic system for watermelon seedlings. Appl. Eng. Agric. 2011, 10, 95-102. [CrossRef]

15. Lee, J.M.; Kubota, C.; Tsao, S.J.; Bie, Z.; Echevarria, P.H.; Morra, L.; Oda, M. Current status of vegetable grafting: Diffusion, grafting techniques, automation. Sci. Hortic. 2010, 127, 93-105. [CrossRef] 
16. Wang, X.Y.; Gu, S. The production experiment of 2jc-500 grafting machine carrying on the watermelon to graft grows seedlings. J. Agric. Mech. Res. 2008, 1, 148-149. [CrossRef]

17. Jiang, K.; Zhang, Q.; Chen, L.P.; Guo, W.Z.; Zheng, W.G. Design and optimization on rootstock cutting mechanism of grafting robot for cucurbit. Int. J. Agric. Biol. Eng. 2020, 13, 117-124. [CrossRef]

18. Ma, Z.Y.; Mu, Y.H.; Gu, S.J. Techniques of automatic grafting of cucurbitaceous vegetables. J. ZhongKai Univ. Agric. Technol. 2012, 1, 48-51. [CrossRef]

19. Lou, J.Z.; Wu, K.; Chen, J.Y.; Ma, G.Y.; Li, J.P. Design and test of self-adaptive stock cotyledons pressing and clamping mechanism for oblique inserted grafting of Cucurbitaceous vegetables. Trans. CSAE 2018, 34, 76-82. [CrossRef]

20. Yang, Y.L.; Li, K.; Chu, Q.; Zhong, L.X.; Jia, D.D.; Gu, S. Air suction clamp structure of rootstock cotyledons for inclined inserted grafting machine and its optimized experiment of operation parameters. Trans. CSAE 2014, 30, 25-31. [CrossRef]

21. Zhu, X.C.; Jin, X.; Yao, B.; Cao, J. Modeling and Design of a frictionless pneumatic cylinder system with air bearings. In Proceedings of the 5th Annual IEEE International Conference on Cyber Technology in Automation, Control and Intelligent Systems, Shenyang, China, 8-12 June 2015.

22. Lou, J.Z.; Li, J.P.; Zhu, P.A. Design and test on growing point removal mechanism of melon vegetable grafting stock. Trans. CSAE 2016, 32, 64-69. [CrossRef]

23. Lou, J.Z.; Li, J.P.; Zhu, P.A.; Lv, G.L.; Wang, M. Optimization of suction head of scion clamping mechanism for vegetable grafting machine. Trans. CSAM 2013, 44, 63-67. [CrossRef]

24. Zheng, W.K.; Dong, J.K.; Zhang, L.; Chen, Z.H. Heating performance for a hybrid radiant-convective heating terminal by orthogonal test method. J. Build. Eng. 2020, 33, 101627. [CrossRef]

25. Bai, J.; Ma, S.C.; Wang, F.L.; Xing, H.N.; Ma, J.Z.; Hu, J.W. Field test and evaluation on crop dividers of sugarcane chopper harvester. Int. J. Agric. Biol. Eng. 2021, 14, 118-122. [CrossRef]

26. Li, H.; Zeng, S.; Luo, X.; Fang, L.; Liang, Z.; Yang, W. Design, DEM simulation, and field experiments of a novel precision seeder for dry direct-seeded rice with film mulching. Agriculture 2021, 11, 378. [CrossRef]

27. Zhang, X.; Bai, S.; Jin, W.; Yan, J.; Shi, Z.; Yu, N.; Yuan, P.; Zhu, X. Design and parameter optimization of an air suction jujube picking and conveying device. Trans. ASABE 2020, 63, 943-954. [CrossRef]

28. Chen, H.T.; Wang, H.F.; Wang, Y.C.; Shi, N.Y.; Wei, Z.P.; Dou, Y.K. Design and experiment of three-leaf type air-suction seed meter with automatic clear and replace seeds features for soybean plot test. Trans. CSAM 2020, 51, 75-85. [CrossRef]

29. Jiang, K. Study on Mechanism and Experimental Device of Splice Mechanical Grafting of Cucurbit. Ph.D. Thesis, Northeast Agricultural University, Harbin, China, 2019.

30. Jiang, K.; Zhang, Q.; Chen, L.P.; Guo, W.Z.; Mou, Y.Q. Simulation design and performance experiment of adsorption block in feeding and positioning mechanism for rootstock. Trans. CSAE 2020, 36, 73-80. [CrossRef]

31. Lou, J.Z. Mechanism Study and Optimization Design of Inclined-Insert Grafting Device of Cucurbita Vegetable. Ph.D. Thesis, Zhejiang University, Hangzhou, China, 2014.

32. Wang, F.; Ma, S.; Xing, H.; Bai, J.; Hu, J. Base cutting energy consumption for sugarcane stools using contra-rotating basecutters. Trans. ASABE 2021, 64, 221-230. [CrossRef] 